\title{
THE TENSILE BREAKING STRENGTH OF PHRAGMITES AUSTRALIS (CAV.) TRIN. EX STEUD. LEAVES AS A CHRONIC IRRADIATION EFFECT
}

\author{
D. Ganzha', D. Ganzha', A. Nazarov³, B. Sploshnoi \\ ${ }^{1}$ Ivano-Frankivsk Department of the Ukrainian Geographical Society \\ ${ }^{2}$ Vasyl Stefanyk Precarpathian National University, Ukraine \\ ${ }^{3}$ State Specialized Enterprise “Chernobyl Spetskombinat”, Chernobyl, Ukraine
}

\begin{abstract}
Tension breaking strength of common reed leaves was studied. Samples of leaves were taken in six aquatic ecosystems in the Chernobyl exclusion zone. In the samples of leaves, the specific activity of ${ }^{90} \mathrm{Sr}$ and ${ }^{137 \mathrm{Cs} \text { was }}$ measured, as well as the accumulation of macro elements of the plant's mineral nutrition. According to the measurement results, the doses of internal radiation from the incorporated radionuclides were calculated. A close statistical relationship was established between the tensile breaking strength of the leaves with respect to their radiation exposure and the reciprocal statistical relationship of irradiation dose to the accumulated leaves to macroelements. It is shown that the tensile breaking strength of the leaves is mainly influenced by the irradiation dose from incorporated ${ }^{137} \mathrm{Cs}$ in the leaves. The data obtained show that the damaging effect of ionizing radiation leads to an increase in the tensile breaking strength of the leaves, and the enrichment with macroelements of mineral nutrition has a radioprotective effect. The results of statistical analysis indicate that the tensile breaking strength of common reed leaves can be considered a reliable test when assessing the irradiation dose of internal exposure from incorporated radionuclides.
\end{abstract}

Keywords: Aquatic ecosystem, biology indication, Chornobyl exclusion zone, common reed, radioecology, ${ }^{90} \mathrm{Sr},{ }^{137 \mathrm{Cs}}$

\section{INTRODUCTION}

In the Chernobyl exclusion zone (Chez), under the influence of chronic radiation exposure, morphological changes in conductive beams and in venation of common reed leaves (Phragmites australis (Cav.) Trin. Ex Steud.) are observed at the micro- and macroscopic levels. It has been established that the effects of morphometric parameters of common reed leaves manifest themselves in a different measure with the same irradiation dose absorbed by leaves and under the influence of non-radiation anthropogenic environmental factors [1]. It can be assumed that changes in venation of common reed leaves under the influence of irradiation dose leads to the fact that narrower, shorter and denser leaves, which occur in places with large levels of aquatic ecosystems radionuclides contamination, are the result of chronic irradiation. Accordingly, as an integral indicator of the morphological effects of chronic irradiation in common reed leaves, the tensile breaking strength in the leaves can be used [2]. Studies have shown a close statistical dependence of tensile breaking strength in common reed leaves depending on the radionuclide contamination of aquatic ecosystems. Unfortunately, there was no reliable connection between the breaking strength of the leaves and their irradiation dose, since the accumulation of radionuclides in the test leaves was not investigated. Instead, an indirect assessment of the accumulation of radionuclides based on the results of the study of other samples of common reed plants taken at the same places in the corresponding season was conducted. This approach did not contribute to establishing a reliable statistical relationship between the irradiation dose in the leaves and their strength index.

The aim of this research is to assess the tensile breaking strength of common reed leaves depending on the level of chronic internal irradiation by incorporated radionuclides and depending on the accumulated macroelements of mineral nutrition in the plant leaves.

\section{MATERIALS AND METHODS}

The samples of common reed leaves were selected in July-August 2017 in 6 aquatic ecosystems of the Chez: lake Azbuchyn, lake Glyboke, lake Daleke, Yaniv backwater of the Prypiat river near the town of Prypiat, cooling pond of the Chernobyl Nuclear Power Plant (NPP basin), alignment of the Prypiat River near Chernobyl. For the research, common reed leaves were selected from 30 to 50 plants on each picket.

The samples were measured by the content of macroelements, $\mathrm{pH}$, conductivity, and specific activity

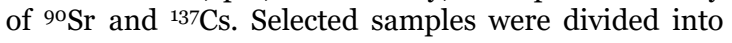

\footnotetext{
"gandyber@gmail.com
} 
two preparations, one of which was dried to an air-dry mass and sent for radio-spectral and laboratory betaradiometric analyzes. The rate of beta particles emitted by the reed canards was measured using a combined radiometer KRK-1 (Russia). The calculation of the total specific activity of beta-emitting radionuclides was carried out in accordance with the recommendations for the analysis of specimens with a thickness of up to $10 \mathrm{~mm}$. The total uncertainty in the laboratory analysis did not exceed $\pm 30 \%$ [3]

The specific activity of ${ }^{40} \mathrm{~K}$ in the samples was calculated from the results of electrochemical analysis of $\mathrm{K}^{+}$ions in aqueous extracts from the leaf samples.

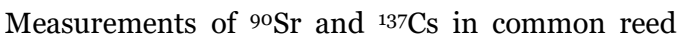
leaves performed by the method of laboratory beta radiometry using a combined $\mathrm{KRK}-1$ radiometer (Russia) and gamma-ray spectrometry using Nuclear Analyzer NC 482-BM (Hungary), as well as the calculated specific activity of $4^{\circ} \mathrm{K}$, were monitored using the example of individual preparations of whole plants in the laboratory of SSE Chernobylsky. The analysis was performed using a spectrometer of beta energy radiation SEB 01-150 and a gamma spectrometer with an analyzer 4900 Nokia LP B and Ge-detector. The total uncertainty in the laboratory analysis did not exceed $\pm 15 \%$.

Based on the measurement results, according to the existing recommendations [4], the irradiation dose rate of internal radiation of common reed leaves was calculated. The irradiation dose was calculated in relation to the wet weight of the sample taken.

From the second preparation, a water extract was prepared directly on the day of sampling, according to the current regulations [5]. The extraction has been carried out for 12 hours at a ratio of weight (grams) sample/water - 1/10. The aqueous extract was filtered and sent to the electrochemical analysis.

The tensile breaking strength of common reed leaves was estimated according to the existing observation experience and the standard used in the technique [6] [7]. It was measured using digital weights at the time of leaf breaking when they were stretched. According to the results of the tests, the ultimate tensile breaking strength (Qp, $\mathrm{kg} / \mathrm{mm} 2$ ) was calculated using the formula;

$$
\mathrm{Qp}=\mathrm{P} \cdot \mathrm{S}^{-1} \text {; }
$$

where: $\mathrm{P}$ is the breaking force, kgs; $\mathrm{S}$ is the crosssectional area of the sheet at the point of rupture, $\mathrm{mm}^{2}$ ( $S=b \cdot h$, where $b$ is the width of the leaf, $h$ is the sheet strength).

The total uncertainty of measurements $(u)$ was calculated in accordance with the recommendations [8] by the formula:

$$
u(\%)=\sum_{c} u_{c}(\%)
$$

where: $u_{c}$ is composing uncertainty of measurement. In this case, we take into account only the factors affecting the random uncertainty components: $u_{c}(\%)=V_{c}(\%)=$ $s \cdot \bar{x}^{-1} \cdot 100$, where $V_{c}(\%)$ is the coefficient of variation; $s$ is experimental sample standard deviation and $\bar{x}$ is the sample mean.
Statistical analysis of measurement results was performed using a software application Past 3.19. (Hammer et al., 2001) to assess the association of pairs of analyzed samples using a comparison test of medians, the coefficients of variation of samples, Spearman's correlation coefficient (rS) and Kolmogorov-Smirnov test (D). Below are descriptions of the statistics and applied tests performed according to the appendix Past 3.19.

The Monte Carlo permutation test was used to accurately estimate the probability of the calculated statistical parameters below. The Monte Carlo significance value is based on 99,999 random reassignments of values to columns within each pair. This value will be practically identical to the exact probability (p) value. The exact value of $p$ is obtained by the Monte Carlo method with probability $\mathrm{p}<0.05$.

Since for most of the data in this study it is not possible to determine the type of distribution, instead of analyzing the means and variances by t-test and $\mathrm{E}-$ test, we used non-parametric tests to compare the medians and coefficients of variation of the samples, respectively.

The two-tailed (Wilcoxon) Mann-Whitney U test (U) is used to identify whether the medians of two independent samples are different. It is a nonparametric test and does not assume a normal distribution, but does assume an equal-shaped distribution in both groups. The null hypothesis is $\mathrm{H}_{0}$ : The two samples are taken from populations with equal medians. The total of these counts is the test statistic $\mathrm{U}$. The program computes an asymptotic approximation to exact value $\mathrm{p}(\mathrm{U})$ based on the normal distribution (two-tailed). $\mathrm{P}=0.5$ was taken as the critical value. Values of $p>0.5$ were taken as those corresponding to Ho.

The data checked for the equal coefficient of variation (CV) in two samples using the Fligner-Kileen test. The null hypothesis $h$ is: the samples were taken from populations with the same coefficient of variation. The program calculates the necessary statistics parameters, based on which the values are calculated $\mathrm{p}(\mathrm{CV})$, as one-tailed and two-tailed. We used the twotailed value of $\mathrm{p}$. If the given $\mathrm{p}$ (normal) is less than 0.05 , the equal coefficient of variation can be rejected. Correlation analysis was performed using Spearman's (non-parametric) rank-order correlation coefficient linear correlation coefficient (Pearson's correlation coefficient) of the ranks.

The Kolmogorov-Smirnov test is a nonparametric test for the overall equal distribution of two univariate samples. The null hypothesis is: The two samples are taken from populations with equal distribution. The hypothesis is rejected if the actually observed value of the statistics D is greater than the critical $p$ and is taken otherwise. The exact value of $p$ is obtained by the Monte Carlo method with a probability a $\mathrm{p}<0.05$.

\section{RESULTS AND DISCUSSION}

In the previous research of the radiobiological effects in common reed, as a rule, irradiation dose calculations were used based on measurements of radionuclides specific activity in whole plants. Such measurements have the mean value of the uncertainty of observations $(\mathrm{V}, \%)$, which make up for ${ }^{90} \mathrm{Sr}$ and 
${ }^{137} \mathrm{Cs}$, respectively $-54 \%$ and $46 \%$ [7]. With such uncertainty of results, it was not possible to find a reliable statistical relationship between the irradiation dose of plants and the tensile breaking strength of common reed leaves. In order to obtain more reliable results, it became necessary to measure the specific activity of radionuclides directly into leaves that were tested to rupture. Mass measurements of the specific activity of ${ }^{\circ} \mathrm{Sr}$ and ${ }^{137} \mathrm{Cs}$ were carried out using the method of laboratory beta radiometry.

3.1. Measurement of specific activity radionuclides and irradiation dose assessment in common reed leaves

For laboratory beta radiometry, common reed leaves were ground in air-dry condition. The ground material was used as a counting preparation for laboratory beta radiometry and gamma spectrometry. Beta radiometry of counting preparations was carried out without a filter and with a radio-spectrometric filter made of aluminum.

The determination of the total specific activity of beta-emitting radionuclides $\left({ }^{40} \mathrm{~K},{ }^{\circ 0} \mathrm{Sr}+{ }^{90} \mathrm{Y},{ }^{137} \mathrm{Cs}\right)$ according to the results of the analysis of the counting drug was performed by the method of laboratory beta radiometry, according to the existing recommendations [7]. The total specific activity of beta-emitting radionuclides was calculated by the formula [7]:

$\mathrm{A}=\mathrm{N} \cdot(\eta \mathrm{m})^{-1}$

where $\mathrm{N}$ - is the sample count rate;

$\mathrm{m}$ - mass sample, $\mathrm{g}$;

$\eta$ - radionuclide pulse counting efficiency, (the product of correction coefficients, which are calculated empirically from measurements of counting samples and standard sources of ionizing radiation without a filter and with a radio spectrometric filter).

The specific activity of ${ }^{\circ} \mathrm{K}$ in the sample leaves was calculated from the amount of $\mathrm{K}+$ ion measured by the electrochemical method. The specific activity of ${ }^{137 \mathrm{Cs} \text { in }}$ counting preparations was measured using the Nuclear Analyzer NC-482 BM (Hungary), according to the technical description of the instrument. The specific activity of ${ }^{\circ} \mathrm{Sr}+{ }^{\circ} \mathrm{Y}$ was calculated by the formula

$$
\mathrm{A}\left(9^{\circ} \mathrm{Sr}+{ }^{\circ} \mathrm{Y}\right)=\mathrm{A}(\mathrm{sum})-\left(\mathrm{A}\left({ }^{40} \mathrm{~K}\right)+\mathrm{A}\left({ }^{137 \mathrm{Cs}}\right)\right)
$$

Considering that ${ }^{\circ} \mathrm{Sr}$ in the samples is in radiation equilibrium with ${ }^{\circ 0} \mathrm{Y}$, the activity of ${ }^{90} \mathrm{Sr}$ was established by the formula;

$$
\mathrm{A}\left({ }^{{ }^{\circ} \mathrm{Sr}}\right)=\mathrm{A}\left({ }^{\circ} \mathrm{Sr}+{ }^{90} \mathrm{Y}\right) / 2
$$

The results of measuring the specific activity of radionuclides in samples show that the natural ${ }^{40} \mathrm{~K}$ varies approximately twice in the studied ecosystems (Table 1). In turn, the specific activity of technogenic radionuclides in samples from different surveillance places varies a hundred times.

Measurements of ${ }^{90} \mathrm{Sr}$ and ${ }^{137 \mathrm{Cs}}$ were carried out by the method of laboratory beta radiometry, which does not exceed $30 \%$.

The specific activity of radionuclides obtained by the method of laboratory beta radiometry $\left(^{90} \mathrm{Sr}\right.$ and

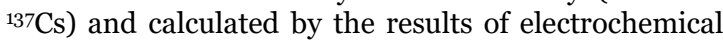
analysis $\left(4^{\circ} \mathrm{K}\right)$ was compared with measurements by gamma and beta spectrometry. A comparison conducted for the three control samples of common reed plants showed that the results of measurements of the specific activity of $4^{\circ} \mathrm{K},{ }^{\circ} \mathrm{Sr}$ and ${ }^{137} \mathrm{Cs}$ obtained by different methods differ by $47 \%, 33 \%, 43 \%$, respectively.

Table 1. Specific activity of radionuclides in common reed leaves obtained by the method of laboratory beta radiometry $\left({ }^{90} \mathrm{Sr}\right.$ and $\left.{ }^{137} \mathrm{Cs}\right)$ and calculated by the results of

\begin{tabular}{|c|c|c|c|c|}
\hline \multirow[b]{2}{*}{ Radionuclide } & \multicolumn{3}{|c|}{$\mathrm{Bq} / \mathrm{kg}$} & \multirow[b]{2}{*}{$\mathrm{V}, \%$} \\
\hline & Min & Avg & Max & \\
\hline${ }^{40} \mathrm{~K}$ & 270 & 390 & 430 & 33 \\
\hline${ }^{90} \mathrm{Sr}$ & 60 & 2000 & 7000 & 26 \\
\hline${ }^{137} \mathrm{Cs}$ & 700 & 16600 & 55000 & 26 \\
\hline
\end{tabular}
electrochemical analysis $\left(4^{\circ} \mathrm{K}\right)$.

According to the results of measuring the specific activity of radionuclides, the irradiation dose of internal exposure to incorporated radionuclides in common reed leaves was calculated (Table 2). A comparison of the irradiation dose of various radionuclides in the leaves showed that the greatest

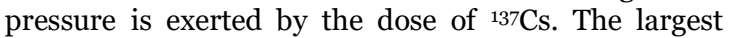
total internal irradiation doses of the leaves are observed in the Lake Glyboke and Lake Daleke ecosystems, the lowest - for the alignment of the Prypiat River. Even under the conditions of the lowest irradiation dose from the technogenic radionuclides observed in common reed leaves collected in the alignment of the Prypiat River ecosystem, the proportion of ${ }^{\circ} \mathrm{K}$ in the irradiation leaves is very small and amounts to $10 \%$. Comparable irradiation doses from ${ }^{40} \mathrm{~K}$ are observed in the NPP basin and Yaniv backwater. In all observed cases, the effect of the irradiation dose from a natural radionuclide ${ }^{40} \mathrm{~K}$ in the Chez conditions is negligible.

Table 2. Irradiation dose of common reed leaves accumulated

\begin{tabular}{|c|c|c|c|c|c|}
\hline $\begin{array}{c}\text { Surveillance } \\
\text { places }\end{array}$ & $\begin{array}{c}4^{40} \mathrm{~K}, \\
\mathrm{mcG} / \mathrm{h}\end{array}$ & $\begin{array}{l}{ }^{90} \mathrm{Sr}, \\
\mathrm{mcG} / \mathrm{h}\end{array}$ & $\begin{array}{c}{ }^{137} \mathrm{Cs}, \\
\mathrm{mcG} / \mathrm{h}\end{array}$ & $\begin{array}{c}\text { Sum, } \\
\mathrm{mcG} / \mathrm{h}\end{array}$ & $\mathrm{k}\left({ }^{40} \mathrm{~K}\right)$ \\
\hline Azbuchyn & 0.0097 & 0.13 & 0.49 & 0.63 & 2 \\
\hline NPP basin & 0.011 & 0.015 & 0.12 & 0.15 & 8 \\
\hline Glyboke & 0.0071 & 0.42 & 2.4 & 2.79 & 0.3 \\
\hline Daleke & 0.010 & 0.13 & 1.09 & 1.23 & 0.8 \\
\hline $\begin{array}{l}\text { Chernobyl } \\
\text { transit }\end{array}$ & 0.011 & 0.0035 & 0.098 & 0.11 & 10 \\
\hline $\begin{array}{l}\text { Yaniv } \\
\text { backwater }\end{array}$ & 0.011 & 0.019 & 0.11 & 0.14 & 9 \\
\hline
\end{tabular}
from the radiation of incorporated radionuclides

3.2. Dependence of the tensile breaking strength in common reed leaves on irradiation dose and accumulation of macroelements

Research of the tensile breaking strength in common reed leaves showed that this parameter changes twice in the places of observation (Figure1)(Table 3). The lowest Qp value is observed in the Yaniv backwater ecosystems and the alignment of the Prypiat River. In both cases, common reed leaves were taken in places that are affected by the urban ecosystems of Chernobyl and Pripyat, which are in a state of demutation, that is, in a state of destruction of man-made infrastructure and the restoration of natural 
cover. These ecosystems are characterized by an increased amount of mineral nutrition elements and the lowest level of irradiation doses among researches surveillance places. Several large Qp values show common reed leaves taken from the NPP basin and lake Azbuchyn ecosystems under the influence of anthropogenic pollution from the Chernobyl NPP, and along with radionuclide pollution, enriched with macroelements of plant mineral nutrition. Maximum values of $Q p$ are observed in the ecosystems of lake Glyboke and lake Daleke, they are associated with the highest levels of irradiation dose and apparently high values of $Q p$ are evidence of the reaction of leaves to the radiation pollution.

Table 3. The strength of common reed leaves on the gap in the field of observation

\begin{tabular}{|l|r|r|r|}
\hline Surveillance places & N & Qp & V,\% \\
\hline Azbuchyn & 31 & 1.3 & 41 \\
NPP basin & 31 & 1.2 & 43 \\
Glyboke & 36 & 1.55 & 46 \\
Daleke & 30 & 1.43 & 28 \\
Chernobyl transit & 13 & 1 & 29 \\
Yaniv backwater & 21 & 0.83 & 34 \\
\hline
\end{tabular}

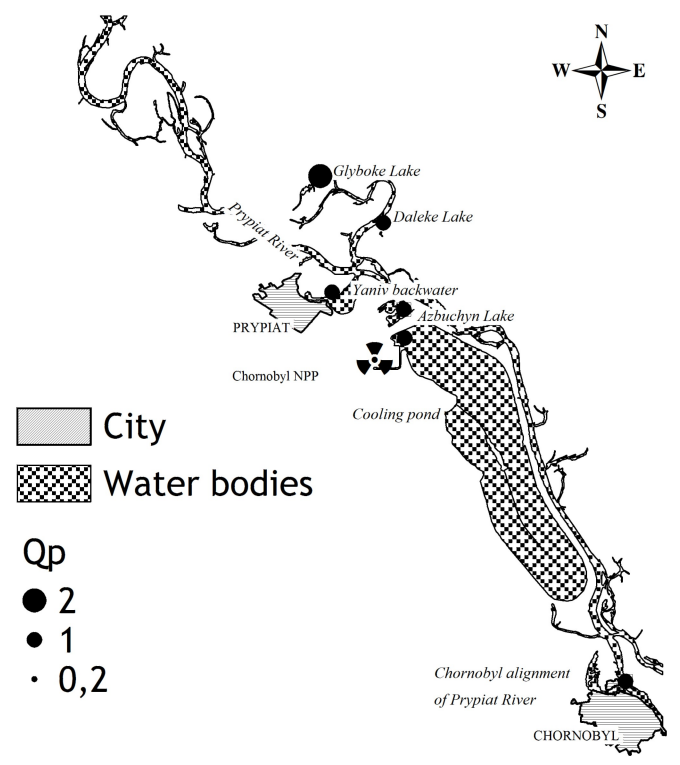

Scale: $\stackrel{1 \mathrm{~km}}{\longleftrightarrow}$

Figure 1. The tensile breaking strength of common reed leaves, selected at sites of observation

The increase in the tensile breaking strength of common reed leaves corresponds to the irradiation dose level of the leaves, which is confirmed by the data of the correlation analysis (Table 4). In this case, a closer relationship $(\mathrm{rS}=0.94)$ of the Qp parameter is observed with respect to the irradiation dose from ${ }^{137 C s}$. Macroelements of plant mineral nutrition act as antagonists to the damaging effects of ionizing radiation, as evidenced by the inverse correlation between the Qp value and the accumulated calcium, potassium, magnesium and ammonium in the common reed leaves. Conductivity, as an integral indicator of the concentration of electrolytes in a solution, also has an inverse correlation with the value of $\mathrm{Qp}(\mathrm{rS}=-0,77)$. Statistical analysis of the distribution of samples of common reed leaves taken from different surveillance places showed that the tensile breaking strength of the leaves has the same coefficients of variation with all the parameters describing the saturation of leaves with macroelements of mineral nutrition (CV (Qp)). On the basis of the irradiation dose in the leaves, the samples from different surveillance places do not have a similarity in the coefficient of variation, in contrast to the same coefficient of variation characteristic to the concentration of macroelements in the leaves. Such a difference in the distribution of data on the basis of the coefficient of variation is explained by the fact that the concentration of macroelements in the leaves of the examined ecosystems rather monotonously changes with a coefficient of variation less than $100 \%$, and the irradiation dose changes by two orders of magnitude, with a coefficient of variation greater than $100 \%$. A distribution threshold is observed between leaves in the Chernobyl alignment, Yaniv backwater, NPP basin on the one side and on the lake Azbuchyn, lake Glyboke, lake Daleke on the other.

Thus, the data obtained reliably show that the damaging effect of ionizing radiation leads to an increase in the tensile breaking strength of the leaves, and enrichment of the leaves with macronutrients of mineral nutrition has a protective effect.

Table 4. Connection of the parameters studied in the samples of common reed leaves with the tensile breaking strength in the leaves (estimated from six surveillance places)

\begin{tabular}{|c|c|c|c|c|}
\hline Parameter & Avg & $\mathrm{V}, \%$ & $\mathrm{rS}(\mathrm{Qp})$ & $\mathrm{CV}(\mathrm{Qp})$ \\
\hline $\mathrm{pH}$ & 7 & 6.5 & n.c. & n.c. \\
\hline $\begin{array}{l}\text { Conductivity, } \\
\mathrm{mS} / \mathrm{cm}\end{array}$ & 0.46 & 37 & -0.77 & 0.16 \\
\hline $\mathrm{Ca}, \mathrm{ppm}$ & 44 & 38 & -0.83 & 0.23 \\
\hline $\mathrm{K}, \mathrm{ppm}$ & 10159 & 20 & -0.92 & 0.13 \\
\hline $\mathrm{Mg}, \mathrm{ppm}$ & 354 & 61 & -0.94 & 0.05 \\
\hline $\mathrm{Na}, \mathrm{ppm}$ & 0.9 & 81 & n.c. & 0.16 \\
\hline $\mathrm{NH}_{4}, \mathrm{ppm}$ & 24 & 44 & -0.54 & 0.24 \\
\hline${ }^{90} \mathrm{Sr}, \mathrm{mcG} / \mathrm{h}$ & 0.04 & 130 & 0.77 & n.c. \\
\hline 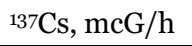 & 0.25 & 128 & 0.94 & n.c. \\
\hline
\end{tabular}

Note rS (Qp) - correlation of the strength value of common reed leaves with the corresponding parameter in the leaves, only reliable correlation values are given; CV (Qp) - equality of the coefficient of variation of the strength value of common reed leaves with the corresponding parameter in the leaves, only those data that confirm the "zero hypothesis" are given; n.c. - no match found

\subsection{Statistical evaluation of the connection between different surveillance places based on the tensile breaking strength of common reed leaves}

Using the method of pairwise comparison of the samples taken from six surveillance places on the basis of tensile breaking strength (Qp) in common reed leaves, the $\mathrm{Qp}$ data were grouped according to applicable statistical criteria. The "null hypothesis" of the Kolmogorov-Smirnov test suggests that two samples are taken from populations with equal distribution. The analysis showed that the samples from the lake Azbuchyn, lake Daleke and NPP pool, as 
well as lake Glyboke and lake Daleke matched the null hypothesis. That is, on the basis of the tensile breaking strength of leaves, the samples from the ecosystems with the highest irradiation dose on plants were combined.

For the distribution of median equality, two tests were used: the Mood median which is a less powerful criterion and a more powerful Mann-Whitney criterion. The null hypothesis implies the equality of the medians of two compared samples. On the basis of the Mood median, the samples were combined with large irradiation dose values in the lake Azbuchyn, lake Glyboke, lake Daleke, and NPP basin. By the more powerful Mann-Whitney criterion, sampling of Qp values from the lake Glyboke and lake Daleke ecosystems were combined with the maximum irradiation dose among the studied plant samples.

The results of the statistical analysis indicate that the tensile breaking strength in common reed leaves can be considered a reliable test for the irradiation dose of leaves obtained from incorporated radionuclides.

\section{CONCLUSIONS}

The possibility of measuring the specific activity of the Chernobyl type beta radiating radionuclides in plant samples by laboratory beta radiometry using spectral filters has been shown.

The data obtained show that the damaging effect of ionizing radiation leads to an increase in the tensile breaking strength in the leaves, and the enrichment with macroelements of mineral nutrition has a radioprotective effect.

The results of statistical analysis indicate that the tensile breaking strength of common reed leaves can be considered a reliable test when assessing the irradiation dose of internal exposure from incorporated radionuclides. At the same time, no difference in the effect of the dose from ${ }^{90} \mathrm{Sr}$ and ${ }^{137} \mathrm{Cs}$ in the studied trait was found.

Acknowledgements: The authors would like to thank D.I. Gudkov, the Head of the Department of Freshwater Radiology of IHB of NAS of Ukraine, Doctor of Biological Sciences, Senior Research Associate, for support in conducting those observations.

\section{REFERENCES}

1. Д. Ганжа, О. Назаров, “Вплив хронічного радіаційного опромінення на жилкування та розташування продихів у листках Phragmites australis (Cav.) Trin. ex Steud,” Вісник Львівського університету, Випуск 69, Львов, Украина, 2015. (D. Ganzha, O. Nazarov, "Influence of chronic radiation exposure on the housing and location of stomata in the leaves Phragmites australis (Cav.) Trin. ex stoud," Bull. University of Lviv, no. 69, Lviv, Ukraine, 2015.)

Retrieved from:

http://prima.franko.lviv.ua/faculty/biologh/wis/69/6/ 14/14.pdf

Retrieved on: Apr. 21, 2019
2. Д. Д. Ганжа, А. Б. Назаров, “Изменение механических характеристик листьев тростника обыкновенного под влиянием хронического радиационного облучения," в Материалы Биологические эффекты малых доз ионизирующей радиации и радиоактивное загрязнение среды, Сыктывкар, Россия, 2014, стр. 210 - 214.

(D. D. Ganja, A. B. Nazarov, "Changes in mechanical characteristics in phragmites communis resulted from radioactive irradiation chronic effect," in Proc. Int. Conf. Biol. Eff. Low Dose Ioniz. Radiat. Radioact. Pollut. Environ., Syktyvkar, Russia, 2014, pp. $210-$ 214.)

Retrieved from:

https://ib.komisc.ru/add/conf/biorad/wpcontent/uploads/2014/01/material biorad 2014.pdf Retrieved on: Jun. 15, 2019

3. М. Т. Максимов, Г. О. Оджагов, Радиоактивные загрязнения и их измерение, Изд. 2, Москва, Россия: Энергоатомиздат, 1989.

(M. T. Maksimov, G. O. Odjagov, Radioactive contamination and their measurement, 2nd ed., Moscow, Russia: Energoatomizdat, 1989.)

Retrieved from:

https://urss.ru/cgibin/db.pl?lang $=$ Ru\&blang $=$ ru\&page $=$ Book\&id $=111343$ Retrieved on: Mar. 30, 2019

4. J. Brown, P. Strand, A. Hosseini, P. Børretzen, Handbook for Assessment of the Exposure of Biota to Ionising Radiation from Radionuclides in the Environment, European Commission, Brussels, Belgium, 2003.

Retrieved from:

https://wiki.ceh.ac.uk/download/attachments/1158021 76/fasset d5.pdf\% 3 Fversion\%3 ${ }_{3}$ 1\%26modificationDat e\%3D1263905014000

Retrieved on: Oct. 6, 2019

5. Корма. Методы определения аммиачного азота и активной кислотности (рH), ГОСТ 26180-84, Апр. 29, 1984.

(Fodder. Determination of ammonia nitrogen content and actual acidity), GOST 26180-84, Apr. 29, 1984.)

Retrieved from:

http://docs.cntd.ru/document/1200024363

Retrieved on: Sep. 9, 2019

6. Бумага и картон. Методы определения влагопрочности (с Изменениями $\mathrm{N}$ 1, 2), ГОСТ 13525.7-68, Июл. 5, 1968.

(Paper and board. Methods for determination of wet strength, GOST 13525.1-68, Jul. 5, 1968.)

Retrieved from:

http://docs.cntd.ru/document/1200018216 Retrieved on: Dec. 21, 2018

7. D. Ganzha, Ch. Ganzha, A. Nazarov, B. Sploshnoi, "Specifics of using phragmites australis for holding a radioecological monitoring," in Proc. 3rd Int. Con. Radiation and Applications in Various Fields of Research (RAD2015), Budva, Montenegro, 2015, pp. $257-262$.

Retrieved from: http://www.rad-conference.org/proceedings.php Retrieved on: Sep. 13, 2019

8. Evaluation of measurement data - Guide to the expression of uncertainty in measurement, 1st ed., JCGM, Paris, France, 2008.

Retrieved from:

https://www.bipm.org/utils/common/documents/jcgm /JCGM 100 2008 E.pdf

Retrieved on: Jul. 13, 2019 